\section{(BE)LONGING MEDIA: MINORITY RADIO BETWEEN CULTURAL RETENTION AND RENEWAL}

\begin{abstract}
The article promotes the growing body of research concerned with the impact of television watching and the uses of other media on the cultural orientation and loyalty of migrant groups. Since diasporas are by definition re-imagined communities, their survival depends on their ability to provide a space for con-

flicting claims of belonging and their willingness to reconcile those differences, and the media provide that kind of multiple narratives and discourses. The article examines radio as that part of diasporic media that for most minority groups in Europe is the most accessible.

Specifically, it is focused on Radio MultiKulti, a public service station targeting Germans and all ethnic minorities in Berlin, and BeurFM, a private station targeting only North Africans in Paris and some other French cities. The author sees in their programming an opportunity not only for cultural survival, but also for

cultural renewal and, in German case, for promoting understanding between different immigrant groups and the German majority population.
\end{abstract}

NABIL ECHCHAIBI

Nabil Echchaibi is a Doctoral Candidate at the School of Journalism of the University of Indiana Bloomington, email: nechchai@indiana.edu. 
In a world where both imagined and physical movements of people and ideas make up the fabric of our social lives, our capacity for cultural change and negotiation has become increasingly inevitable. There is today a gradual awakening in academe to the limitations of conceptualisations of culture as bounded and monolithic. Globalisation has accelerated such a realisation as it influences and even dislocates national cultural identities but, as Hall argues, only in the sense that it has a pluralising effect, suggesting new alternative positions of identification (1992). This is particularly true in the case of diasporic subjects who usually resist singular belonging. Their experiences of a suspended sense of belonging compounded by multiplying globalisation processes have increased their resources and diversified their attachments. There is perhaps no more opportune time to rejoice and celebrate the looming end of the reign of essentialist thinking, at least among a few researchers working with subjects situated between cultures of origin and countries of settlement. Ironically, many of those celebrating themselves perpetuate an essentialist discourse that reifies the either-or positioning of hyphenated identities.

Much of the recent theorising in support of the fluidity of culture remains largely muffled by a debilitating bi-polar logic that allows identities to evolve only in distinct, oppositional directions. Such logic is reminiscent of political conceptions of culture in everyday discourse, which are notoriously known for excluding any possibility of mediation and reconciliation between different cultures. Huntington's much cited article: "The Clash of Civilizations" is a leading example of this discourse. In his view, current world conflicts are indicative of his thesis that cultures are primordial and that differences between them are simply unbridgeable (1993). What is most interesting about Huntington's argument is that people are not responsible for this clash of civilisations. The clash here is posited as a passive process because cultures are endemically different and irreconcilable.

Although Huntington's sweeping suggestions have come under heavy attack since the publication of his article in Foreign Affairs, much of his assumptions have been projected onto migrants and diasporic communities who, following the logic of innate cultural conflicts, are only capable of reproducing their cultures of origin in their imaginary fixed state. This explains the current phobia raging in European public opinion about the virulent effects of building mosques, temples, minority cultural associations, and erecting parabolic antennas to watch television from home. Clearly, hyphenated identities: French-North African, British-Asian, German-Iranian, or German-Turk, or else European-Muslim highlight not the fluidity of such identities, but only their "natural" inclination toward collective attachment. The hyphen, instead of serving a connecting function that describes the emergence of hybrid identities, becomes just another form of identification that renders the relationship between the two constituents not only fragmented but oppositional as well.

I do not wish to imply here that home becomes an empty concept for immigrants once they leave. On the contrary, the relationship between the "home" and the "host" is a staple component in many migrants' everyday experiences, but as I shall argue in this paper, this relationship is never problematised or experienced in a uniform way. As long as we persist in conceiving of north Africans in France, Turks in Germany, Asians in England, or Hispanics in the US as unified and homo- 
geneous and continue to believe that their organised cultural spaces are necessary sources of collective identities, our understanding how these identities are formed and negotiated will remain regrettably thin. Clearly, the spaces immigrants create constitute an important site where the initial conflicts between "home" and "alien" are revealed, discussed and possibly resolved and as such deserve our attention but beyond the visible aspects of difference. As Ayse Caglar put it in an excellent article that reads more like a plea to put a halt to the ongoing fixation with that which is visibly "ethnically different:"

\section{My point is that this evident visibility comes to dominate our own theoretical horizons as anthropologists and sociologists almost as much as it does those of the racists, ethnic brokers or politicians who seek to control, resist and domesticate the spatializing process itself. To "write against culture" in this context, in which space is a powerful metaphor for sociality, is to locate other, more invisible, processes that go towards the creation of culture and identity $(1997,177)$.}

The media in this context, and particularly that produced in diaspora, constitute a key site for identity formation. As Ien Ang put it: "It is by recognizing the irreducible productivity of the hybrid practices in the diaspora that China; the mythic homeland, will then stop being the absolute norm for authentic Chineseness against which all other Chinese cultures of the diaspora are measured" $(1994,16)$. My research on diasporic radio is not only a way of recognising this productivity among diasporic communities, but it is also an attempt to make the still invisible visible and move beyond what seems to be an ethnicisation of the migration research agenda.

\section{Radio: Immigrants' Public Sphere}

Our memories of Europe have usually invoked images of empire and expansion, but the idea of Europe today has become more one of retrenchment. There is growing nostalgia for an imagined Europe unified around shared values and traditions. The ongoing reification of boundaries at the transnational level is functioning in tandem with the disturbing rise of cultural fundamentalism and ethnic particularism. Immigrants are increasingly seen as a source of social disturbance and economic burden and opinion polls in many countries are showing a significant unease with the growing visibility of foreign cultures.

Dealing with this presence has been the subject of arbitrary policies that have sent mixed messages on how immigrants should live in their host societies. From assimilation to integration to multiculturalism today, there seems to be no consistent framework for these minorities to participate in the political and social construction of European countries. There is, instead, a growing anxiety about the cultural withdrawal of immigrant groups into their home culture and a decreasing willingness to integrate into the host culture. Recent developments in media technology - satellite television and transnational media - are often blamed for isolating ethnic minorities in a debilitating cultural enclave that prevents them from interacting with the host society. Such accusations indicate a lack of understanding of how immigrants not only use but also produce media to cope with complex issues of identity and difference. 
There is today a growing body of research concerned with the impact of watching home television on the cultural orientation and loyalty of migrant groups (Hargreaves, Caglar, Aksoy, Naficy, Gillespie and others). While research in this area needs to be multiplied in order to problematise generalisations beyond the image of ethnic families sharing a common cultural space, fixed on their home culture and completely removed from the host society, I suggest another area that has received very little attention so far. Diasporic media (media produced from and by diasporic groups) have often been viewed as simply a means through which information of interest can be exchanged, or a means for preserving moribund cultures. By reducing these media to a communitarian logic of bonding, we are failing to understand their instrumental role in helping redefine and challenge the identity and boundaries of a diasporic community. Diasporas are by definition reimagined communities, constructed around multiple narratives and discourses. Their survival depends to a large extent on their ability to provide a space for conflicting claims of belonging and their willingness to reconcile those differences.

I have chosen to examine radio as part of these diasporic media because, for most minority groups in Europe, it is the only medium available to fulfil these purposes. Literature and cinema have also served along the same lines, but their impact as well as presence are not as constant and maybe not always accessible. I use diasporas in the plural because I'd like to underscore an inherent distinction in the concept itself that seldom appears in recent conceptualisations of the term. First, state policies and the socio-political acceptance of ethnic minorities in a given society heavily affect minority cultural activities and media production. Thus, France's colonial history and its pervading philosophy of assimilation, now tainted with a new multiculturalist discourse, variously dictate the institutional frameworks and cultural climate in which minority media can operate. Conversely, Germany's lack of colonial experience and the ensuing inconsistency of its immigration policies help in shaping the operations and goals of these media with all the implications this entails on their reception. Second, there is a tendency in diasporic studies to conflate different experiences under the common heading of diasporic reality. There is certainly a point of confluence in a diasporic community, but experiences are lived and relived through different referential vantage points like gender, race, religion, class, language, and generation. Failure to account for these variations is a regressive move towards a closed notion of identity and culture as singular and primordial. My use of diaspora in this sense is as multiple as these experiences, and my point of anchorage, to borrow Ien Ang's term, is where you're at rather than where you're from.

With this notion in mind, I have decided to focus on radio MultiKulti, a public station targeting Germans and all ethnic minorities in Berlin, and Beur FM, a private station targeting only North Africans both in Paris and a few major French cities. Radio MultiKulti was first created as a public-service reaction following a mounting wave of xenophobia and violent attacks against foreigners in the Brandenburg federal state, of which Berlin is the capital. One of its main concerns is to educate the German public and minorities on the benefits of a multicultural society while preserving the cultural identity of foreigners. In contrast with this top-down approach to minority broadcasting, Beur FM, founded and run by North Africans themselves, started as a grassroots reaction to years of marginalisation, 
racism, and misrepresentation in French mainstream media. Its mission is rather particularistic, but one of its goals is to facilitate the integration of its listeners into French society and help them reconcile the cultural contradictions they experience in that society.

\section{Diasporic or Ethnic Media: What's in a Name?}

Diasporic media have received little attention in the field of media studies. Instead, studies of race and representation in mainstream media fill up the bulk of research in this area. I do not wish to downplay the importance of such research, but I would like to underscore an equally, if not more significant domain which is in need of urgent attention - the media that serve a particularistic function and their role in both integration and the maintenance of difference. Are these types of media necessarily secessive, as they have been said in the past by politicians and researchers alike? Are they by definition instruments of cultural survival, and if so, what kind of culture are they seeking to preserve? How do they define diaspora without reifying the notion of cultural purity? Do they provide a real public sphere for minorities? How is the public radio different from the private radio in representing minorities? How do they legitimise their position as representatives of that community? How do they negotiate the conflict between insertion, separatism and hybridity? Who listens to these radio stations and what are the effects on their audiences? Before attempting an answer to these questions, let me first address what I consider to be a crippling defect in the sporadic research in this area.

The concept of diaspora enjoys a significant, though relatively disputed, currency in contemporary cultural theory. For many years, the term was synonymous of the dispersal of Jews, thus giving it an almost definitive meaning of a group of people forced to leave under a threat of violence or death; their consciousness created and reinforced by common origins, shared experiences of displacement, and a material or symbolic attachment to the homeland (Safran 1991). Though still under-theorised, diaspora has come to signify a much broader sense of movement, as well as a challenge to the limits of fixed boundaries. Anthropologists like James Clifford, among others, have shown the constraints implied in using definitive models of diaspora and offered a more open conceptualisation that includes a new type of movement in the modern era of exiles, political refugees, immigrants, and ethnic minorities. The value in redefining the term lies in resisting a rigid prescription of what constitutes a diaspora, but the fixation with defining what falls inside or outside the term itself, a highly theoretical process so far, brings about issues of description versus construction. Following well-established critiques of narratives of cultural fixity and given new global conditions of mobility, there is little conceptual value in trying to make a particular diaspora fit within a fixed ideal type. This obscures the temporal process of change as "societies may wax and wane in diasporism, depending on changing possibilities, obstacles, openings, antagonisms, and connections-in their host countries and transnationally" (Clifford 1997, 249).

Similarly, Avtar Brah (1996) makes an important distinction between a desire for the homeland, a criterion par excellence of diaspora as it is commonly used, and a homing desire. Not all diasporas or individuals within a diaspora express this desire through a wish of return to a place of origin. Home, in this sense, is also the lived experiences within a locality. It is not singular as the place of origin, but 
derives from the intersection of multiple cultural references. Thus, to borrow Brah's example, a French young woman of North African origins may feel more at home in Paris or Marseilles than in Casablanca or Algiers, but she might overplay her North Africanness only to resist a culture of racism that excludes North Africans from French society. Another young woman with the same background might respond by affirming a strong French-North African identity.

Talking about a somewhat similar experience of being a Dutch-born, raised in Indonesia, of Chinese parents, and not speaking Chinese, Ang says: "If I am inescapably Chinese by descent, I am only sometimes Chinese by consent. When and how is a matter of politics" $(1994,18)$. "Home" can be articulated in a variety of ways, from different positions, under different socio-political and economic circumstances, and with a varying level of involvement in a collective diaspora. It is precisely this variation and mixture that is rarely accounted for in diasporic studies. There is clearly no uniform model for diaspora and insisting on finding one will prevent us from understanding how diasporas are invented and re-imagined within different localities.

By foregrounding the homeland aspect of a diaspora and its experiences of displacement and rootlessness, there is a risk of shadowing the political struggles within a diaspora to re-define the local, the place they now call home. The myth of the homeland, is quite a stubborn concept in the politics of diaspora, not because it is inevitable or a natural inclination for members of a diaspora, but, as I would argue in this research, because there is an outside pressure that forces such identification. I am not implying here that identifying with the homeland is in any form regressive, but in many cases, it is a reaction to marginalisation and exclusion in the host society. There is an urgent need, therefore, to shift our focus away from a fixation with the point of departure (the homeland) to the point of arrival, which for many members of diaspora is primarily a point of departure. The fact that diasporas are growing and the flow of immigrants into Europe is constant somehow delays this shift. Research in this area, all too often, begins and ends with the premise of diaspora as the fragmented variation of an "imported racial essence" (Gilroy 1991).

It is, therefore, by problematising the relationship between these two points of reference (departure/arrival), a critical process already in place for many diasporic communities, that we can better document the potential for productivity and creativity within a culture that lies at the intersection of different cultural forms. This is what Bhabha calls "third space," an opportunity made out of a necessity of translation from different references. It is the space where the contradictions and conflicts arising from the existence of the home culture and the host culture, and also global culture, are negotiated and resolved. "For me the importance of hybridity is not to be able to trace two original moments from which the third emerges, rather hybridity is the third space which enables other positions to emerge" (Bhabha 1990, 211). This is, however, by no means a happy process, as the recent romanticisation of hybridity might lead to conclude. It is, indeed, at times a painful and tiring process whereby diasporic subjects are constantly engaged in what Safran calls an "intellectualisation of an existential condition." Of course, not all diasporas or members within them are involved in such an intellectual exercise as some seek refuge in an imaginary past or seek to belong by deliberately rejecting their origins. I am 
more interested in those who seek to reconcile and build beyond the two frames of reference available to them.

In a similar vein, the persistence in using the term "ethnic" to identify minority media not only evokes the notion of uncontaminated identities but reduces a potential for creativity and a way of dealing with conflicts of difference to what Gilroy calls "the simple process of invariant [cultural] repetition" $(2000,13)$. The little interest diasporic media have garnered among media scholars is somewhat indicative of this unfounded view. How else can we explain why radio stations like radio Sunrise in London and Radio Beur in Paris and others like them on the air for more than 15 years have never been submitted to research, except for few non-academic publications? It is true that diasporic communities themselves can't resist the temptations of essentialising their cultures and there are examples of that in the media as well. Hamid Naficy's research on exilic media among Iranians in Los Angeles is a good case in point. Exilic television, music videos, radio programs and films, he maintains, capitalise on a highly-marketable condition of nostalgia and fetishisation of the homeland as it existed before the Islamic revolution because for many such a condition constitutes a defence mechanism against the image of Iran and Iranians in American mainstream culture (Naficy 1993). Naficy provides an example of diasporic agency whereby media offer both a space for conscious resistance as well as a symptom of an exilic reality. What may appear on Iranian exilic television and cinema as a "mimicry" of a purely imagined past may also be a strategy of defence and resistance. It is as Naficy explains here a rite of passage from ambivalence to clarity:

Ambivalence, mimicry, and hybridity are not permanent and static things or states. They are only strategies, and for them to be productive as modes of resistance, they must be dynamic and capable of change in response to changing exigencies... With the crossing of cultural and psychic thresholds, the exiles emerge potentially less ambivalent toward the dominant culture and less intensely focused on the home culture. They might then have the necessary psychic as well as social confidence to have "a bit of this and a bit of that," to create a third syncretic culture without being totally unattached and weightless hybrids $(1993,195)$.

In highlighting the ethnicity of diasporic media heedless of its functional value as shown in Naficy's example, we risk reducing this important space to a regressive and potentially dangerous form of parochial ethnic belonging. Ethnicity and culture, to go back to Huntington's argument, cannot be detached from their territory of origin. In other words, cultures travel only to remain pure and intact. From such biases arise research designs that conflate distinct and evolving diasporic realities under the banner of "cultural continuity." Thus, North African migrant women can only be addressed in terms of the Veil and independence from Muslim patriarchy; a similar continuity is implied between the North African diaspora and second/third-generation French or German-North Africans. Satellite television, under this explanatory framework, can only be a deterrent to integration since exposure to home culture is by definition a sign of isolation.

This fixation with ethnicity is also related to the ongoing reconfiguration of Europe that is driven by a growing nostalgia for an imagined unified Europe with shared values and traditions. Despite the challenge such a reconfiguration poses 
to the national sovereignties of individual countries and regional identities, there is a growing sense that Europeans need to celebrate their cultural commonalities and eschew all regional differences in order to provide the ideological support for the success of European economic and political union (Godard, Llobera and Shore 1994). Such prescriptive politics of cultural belonging at a transnational level has made it difficult for migrants to fit in Europe simply because their origins fall outside of an ideal circle that is referred to as "fortress Europe."

\section{BeurFm: Beyond Ethnic Compartmentalisation}

Faced with the high costs of television production and marketing, immigrants in France have turned to radio ever since the state ended its monopoly over broadcasting in 1981 (Derderian 1997). North Africans, who account for $40 \%$ of the country's 5 million immigrants (INSEE 1994), have been particularly active in creating radio stations, especially in Paris and Marseilles as an attempt to counter-balance their marginalisation in French mainstream media. There were about 12 stations broadcasting to the North African community alone in 1991, and, according to the latest statistics, Arabic speakers filed 23 applications for a frequency in 1987 and 19 between 1991 and 1992. Most of these stations differ in style (informative, educational, entertainment), language (Arabic, Berber - a dialect widely spoken in North Africa - or French), and mission (cultural/religious, preservation or integration). The experience of these community radio stations, as they came to be called, has been extremely beneficial in the sense that they have transformed quite radically the French public sphere and provided vital spaces for free expression.

Radio Beur, currently Beur FM, first started in 1979 as a pirate station, then turned into a community radio in the 1980 s before it became a commercial station in 1991. It defines itself as a multicultural institution seeking recognition of all marginalised groups in France, including migrant communities. All of its announcers are of North African origin and its official language has changed over time from Arabic and Berber to French. Today, the station claims a particular following among second-generation migrants whose knowledge of their parents' languages remain rudimentary at best (Derderian 1997). The choice of language among most minority radio stations is heavily influenced by how much financial support they can derive from the state. Faced with a highly competitive environment, with about 1,200 commercial stations, most minority radio stations depend on state and local subsidies provided by a public agency responsible for promoting the integration of immigrants and their families into French society.

Radio Beur filled a cultural void in the North African community in France. For over a decade, the station served as a stage for creative beur artists and their music and theatrical performances. For the first time in the history of migration in France, there was a forum where young people of minority origin, particularly North African, could expose their talents. Shows such as Triptyque featured Beur literature and cinema, Les Beurs et la Plume allowed listeners to contribute with their own poetry, and La tribune de Radio Beur gathered artists and intellectuals, both North Africans and French, to talk about racism, education, unemployment, and other social problems.

To meet the challenge of fierce competition of the 1990s, Beur FM was forced to rethink the format of its programs and model its output more one a standardised 
music and brief news style. There have been a decrease in the number of programs for which Radio Beur was extremely popular, but Beur FM still claims a high number of listeners of about 400,000, half of which are in the Parisian region alone. Part of the success of Beur FM's new format is related to the strong appeal of CNN's version of quick news and MTV's version of music. Radio has to adapt to its listeners by focusing more on music, not Algerian, not Moroccan, not Tunisian, not Western, but beur music. Beur FM extended beyond the framework of station programs and got involved in the music industry to promote beur artists and introduce them to the French public. Its campaign had proven effective as beur music is expanding beyond the confines of its ethnic origins.

The producers in BeurFM are conscious of the danger of ethnic compartmentalisation. They define their radio as a multicultural institution seeking recognition of all marginalised groups in France, including migrant communities. All of its announcers are of North African origin and its official language has changed over time from Arabic and Berber to French. Today, the station claims a particular following among second-generation migrants whose knowledge of their parents' languages remain rudimentary at best (Derderian 1997). The choice of language among most minority radio stations is heavily influenced by how much financial support they can derive from the state. Faced with a highly competitive environment, with about 1,200 commercial stations, most minority radio stations depend on state and local subsidies provided by a public agency responsible for promoting the integration of immigrants and their families into French society. Based on this agency's conception of integration, choosing French as broadcasting language is an important step forward (Hughes and Reader 1998). Other stations, for whom state financial support is not as crucial to cover their operating costs, still choose French to avoid any contentious debates over what North African language to choose, Arabic or Berber. This was the case for BeurFM in the 1980s which many Arab listeners accused of having a strong Berber bias. In an interview, Bousaa, an Algerian music DJ describes why he finally decided to leave the station:

Most of the programs were in Berber, which the Arabic-speaking listener did not necessarily understand. I wanted to play a little of everything: Arabic, Kabile (Berber region in Algeria), and Anglo-Saxon music. It was at Radio Beur that I discovered that even within our own community there could be an anti-Arab racism (Bousaa, cited in Derderian 1997).

The value of BeurFM, despite frequent slippages into essentialism of North African cultures, is that it opens up a much-needed space for young people to address their concerns over the pulling forces of cultural retention on one side and the forces of unconditional assimilation on the other. Its celebration of the North African identity is not meant as a retreat into the bounds of a given cultural identity, but it's rather an unwavering statement against the essentialising inclinations of the French assimilationist machine. The daily discussions and the diverse panels of guests the radio hosts reveal, most of the time, a mature and critical perspective not only on political issues but also on internal cultural and religious issues. BeurFM has become a public forum that encourages North Africans in France to open up the bounds of their cultural identities and renegotiate their beliefs in a way rarely experienced in their home countries. Opening up the airwaves for more minority media like BeurFM will not necessarily end up in a "simple process of 
invariant [cultural] repetition." On the contrary, it could become an opportunity for cultural renewal and not only cultural survival, as is often believed.

\section{Radio MultiKulti: Representation from Above}

The fall of The Berlin Wall and the arduous integration of the former GDR into the Federal Republic have increased the need for minority and intercultural programming. The challenge of unifying the two Germanies, which for about forty years had been exposed to opposite ideological cultures, was compounded by the task of providing welfare benefits to a growing number of immigrants. This put pressure on a social welfare system already drained by the exigencies of unification and caused a stir, particularly among easterners who thought their economically weak Länder were more deserving of the money given to foreigners. The euphoria of unification was quickly interrupted by an increase in violence against immigrants and a rise of extreme right-wing groups with strong Nazi inclinations. Public-service broadcasting was quickly assigned this integrative mission of bringing all Germans and foreigners together. By 1998, ZDF's Nachbarn, which by then had stopped importing programmes from the immigrants' countries of origin, was renamed Schwarzrotbunt (BlackRed Multicoloured), a playful reference to the colours of the German flag symbolising the multicultural Germany the program hoped to represent. ARD's Ihre Heimat, unsere Heimat (Your Home, Our Home) was also renamed Babylon so as to counter the bounded connotations of the term "Heimat" and better represent the immigration reality within German society. These efforts towards multicultural programming, however, were not matched by appropriate screening times, which for the most time meant either early Saturday morning, or Sunday afternoon.

Meantime, satellite technology had made major inroads in providing immigrants with television channels from their home countries. There was a fear such a development would draw audiences away from not only public-service minority programming, but also from German media in general. This was bound to cause an undesirable isolation of the migrant population and seriously thwart all efforts towards integration. Producers were concerned the increasing availability of transnational media, particularly from Turkey and the Arab world, would turn the attention of migrants away from their life in Germany and more to a home setting that is more imaginary than real. If foreigners were fixated on home media, then who would represent their reality in the host country?

In Berlin, the Sender Freies Berlin (SFB) public-service broadcasting corporation decided to take up this responsibility by launching a new radio station in 1994. Radio MultiKulti first began as a three-year experiment based on an ambitious plan to increase the media's role in a multicultural society. Broadcasting 24 hours a day on terrestrial frequency, MultiKulti deployed its programs to fulfil a double mission of serving the basic needs of different immigrant groups and promoting understanding among the German majority population (Vertovec 1996). With programs in 18 different languages (representing all Berlin's immigrants), an all German-language program stretching into the afternoon with studio debates on aspects of multicultural life in Berlin, and a nightly music program that features everything except Anglo-American music, MultiKulti serves a clearly integrative role in the city. In 1997, the station was ensured permanent funding as a testimony to 
its success in Berlin and the role model it has started to play for other radio stations across the country.

The choice of Berlin as the setting for MultiKulti was not a coincidence. Since the early 1900s, Berlin has always attracted foreigners from all over the world. In the 1920s, the city became a popular hub for foreign artists and intellectuals who enjoyed the state's promotion of museums, theatres, operas, newspapers, publishing empires, political cabarets, and film studios. The impressive rebuilding of Berlin following the misery of post-war years also attracted workers from East European countries who came looking for better job opportunities. In fact, one of Berlin's most densely-populated and colourful districts (Kreuzberg, often nicknamed "Little Istanbul" because of a strong Turkish concentration) was known at the turn of the century as the Easterners' neighbourhood. But despite the presence of foreigners in Berlin from the Huguenots to the Jews, Bohemian Protestants and the Polish and eastern German migrants, Berliners have not always been very welcoming to newcomers, particularly with those who are racially different (Richie 1998). Currently, about 440,247 immigrants, representing 184 countries, call Berlin home (13\% of the city's total population). Almost one-quarter are under 18 and more than 60 percent of legally registered foreigners under 18 were born in Germany, a phenomenon German officials prefer to call "immigration by birth."

Radio MultiKulti came, therefore, as an answer to this ever-changing social structure. The purpose of its multicultural program was (and still is), as summarised here by the radio's Director, Friedrich Voss,

...to pursue three goals: Firstly, it was to offer a forum for ethnic communities to retain and secure their identities, secondly, it was to provide extensive information on Berlin as a center of vital interest, offering services and guidance, and thirdly, it was to further better integration, which for the ethnic communities meant: sustaining as much as possible and giving up as much as necessary of their originality. It was not going to be a melting pot, but rather a salad bowl (Voss 2000,3).

There are signs, however, that the salad bowl is not a preferred outcome for the country's conservative party (CDU), whose parliamentary leader, Friedrich Merz, has recently sparked a heated debate by laying out the details of what he termed "Leitkultur von Deutschland" (leading, or hegemonic, culture of Germany). "Foreigners," he said, "must conform to Germany's mainstream cultural values if they wish to settle down here" (Joffe 2000). For more than two months after this most controversial declaration, MultiKulti hosted a discussion on the ideological implications of who is "German" and whether a unified German culture discourages or encourages integration. With its presumably minority/majority outreach, MultiKulti conceives of itself as a true integrative tool with vested interests in both Germans and immigrants.

Radio MultiKulti first began as a three-year experiment based on an ambitious plan to increase the media's role in a multicultural society. Broadcasting 24 hours a day on terrestrial frequency, MultiKulti deployed its programs to fulfil a double mission of serving the basic needs of different immigrant groups and promoting understanding among the German majority population (Vertovec 1996). With programs in 19 different languages (representing all Berlin's immigrants), an all German-language program stretching into the afternoon with studio debates on as- 
pects of multicultural life in Berlin, and a nightly music program that features everything except Anglo-American music, MultiKulti serves a clearly integrative role in the city. In 1997, the station was ensured permanent funding as a testimony to its success in Berlin and the role model it has started to play for other radio stations across the country.

Despite well-meaning attempts from the producers to sensitise Berliners to the values of multicultural society, MultiKulti still bears the mark of a political culture that favours top-down, paternalistic resolutions to issues of minority representation and self-expression. On the one hand, it is certainly encouraging to see the public media sector in Germany still clinging to minority programming when most European public media have simply given up on that fundamental role. On the other hand, the persistence of the public sector in exclusively upholding this right and the absence of other private radio stations for minorities in Germany-except for Radio Metropol, a fully-commercial Turkish station that started only in 1999 despite years of Turkish presence in that country- beg for a more important question. Who does MultiKulti represent given its minority/majority outlook and why insist on a top-down approach?

In a sense MultiKulti seems misfit for Germany and maybe more appropriate for a country like France given the political cultures and integration philosophies of both countries. Likewise, BeurFM would have made more sense in Germany. Unlike in France, Germany lacks a prescriptive model of assimilation. Its social policies aim more at safeguarding the distinct cultures and languages of "foreigners" in view of their "temporary" sojourn despite decades and generations of immigrants' presence in many German cities. Immigrants are therefore encouraged to preserve links with their country of origin and German public schools offer help to foreign students to keep in touch with their parents' language and culture through special classes. Such services could well benefit immigrants and their children deal with problems of estrangement and generational conflicts, but it is the intention behind their implementation that makes the remedy worse than the illness. Germany has never conceived of itself as an immigration country despite its 7.2 million immigrants. Its social policies and citizenship laws prolong, rather fastidiously, the temporary nature of immigrants' presence and discourage any attempt by first, second, or third-generation immigrants to settle down and participate in German society on an equal basis.

The programming format of MultiKulti which attempts to accommodate the information needs of all ethnic minorities in Berlin, negates at times the modern, cosmopolitan picture the station producers are keen on drawing of their city as explained here by the Senior Editor, Wolfgang Holler:

The foreign language program is meant only for some ethnic groups who need programs in their home language for their cultural identity. We decided for the biggest ethnic groups, but we decided as well that some ethic groups do not need a special program in their language like the Danish people or Scandinavian people. It's not necessary for them because they speak brilliant German normally. They are mostly highly educated. They are coming for a job. We looked where this special program is really necessary, so we decided for 19 different groups (my interview, 2001), 
While the logic behind which ethnic group needs special attention is arguably sound, the fixation with cultural retention of some ethnic groups as opposed to others bears overtones of political conceptions of culture as bounded, particularly when retention is assumed for a select group of migrants. The German programming, which features discussions, at times highly intellectual, of cosmopolitanism and cultural difference seems to be implicitly targeted at a German audience. The separation between these two programs may send an awkward message to minority listeners who might be tuning in only when their language program is on the air, which could mean half an hour or one hour daily, twice or once a week depending on the size of each ethnic community. Despite the repeated claims by the producers of MultiKulti that the radio is very popular among migrants and Berliners alike, most of the people I talked to during my 5-month stay in Berlin either have not heard or barely heard, or else listen occasionally to their own language programs. It is impossible to know for sure how many foreigners listen to MultiKulti because they are simply not included in audience surveys in Germany. The most recent survey shows that the station accounted for only $0.7 \%$ of the audience share in Berlin (Vertovec 1996).

The German program of MultiKulti seems to have a special following with an educated elite among foreigners and Berliners alike. Its limited reach, however, makes the radio's mission of educating average listeners-foreigners and Germans - a bit hard to achieve as highlighted here by Simo, a university student of Moroccan origin.

Simo: ... I from time to time listen to Multikulti's debates on racism with my German wife. We like to see there are people like us in Berlin who are culturally open-minded and tolerant. The problem, however, is not only that many people are not willing to listen, but also that many are not equipped enough to understand the depth of those debates and frankly not only among foreigners but Germans as well (my interview, 2001).

This narrow audience scope compels us to rethink MultiKulti's claims of minority representativeness. In other words, how does MultiKulti legitimise its role as the voice of ethnic minorities in Berlin? Do minorities indeed perceive MultiKulti as a forum for self-expression and better representation?

In an interesting parallel to the nature and development of the MultiKulti project, some German Länder have already experimented with the organisation of diversity in devising an Islamic curriculum for public primary schools. In the region of North Rhine Westphalia, for example, the Ministry of Culture, Education and Church Affairs, has responded to Turkish Muslim groups' increasing demands for the establishment of Islamic religious schools by appointing an agnostic man with a Jesuit Catholic family background at the head of a commission comprised mostly of non-Muslim Germans to develop the curriculum (Schiffauer 1997).

There was an attempt here at integrating Muslims into civil society and control the differences among Islamic groups, but the question arises: "Is it Islam or some imaginative construction of what Islam might be that is reconstructed in this way?" (Schiffauer 1997, 157). Why not give Muslim Turks in Germany a chance to develop the curriculum themselves, or else why not ask the Office for religious matters in Turkey, which upholds a modern, secular Islam? It is not the accommodation of Islam into civic space that is unusual here, but rather the insistence that the task of designing the curriculum should be placed in the hands of non-Muslim German civil servants. Once again, this is the distinctive signature of the German 
state tradition, which would allow for the inclusion of Muslims in a new national German culture only if their values can be shown not to upset the ethos of the German state. In other words, there should be no conflict between being a good Muslim and being a good German (Schiffauer 1997).

In the case of MultiKulti, it came only as natural that the task of giving a voice to ethnic minorities in Berlin be placed in the hands of the German public broadcasting authority with minority journalists working as bridges between the two. There is a strong concern in German politics, probably more so than in France, to regulate and control the process of integration, lest there should arise too much heterogeneity. There is almost a fear that granting radio licenses to different minorities in Berlin might lead to a ghettoisation of the airwaves, which explains why there are none, making MultiKulti the ultimate voice for migrants and minorities with or without their consent. My point is that if the German political culture demands of these ethnic groups to reach compromises and some level of conformity in order to integrate effectively, then maybe it should allow also for forums like radio stations produced by minorities themselves where differences and incommensurabilities can be raised, discussed, and resolved. So far, MultiKulti seems to be more about resolving those differences for Germans, who have yet to cope with an increasing presence of "Ausländer."

\section{References:}

Ang, len. 1994. On Not Speaking Chinese: Postmodern Ethnicity and the Politics of Diaspora. New Formations 24, 1-18.

Bhabha, Homi. 1990. Nation and Narration. London: Routledge.

Brah, Avtar. 1996. Cartographies of Diaspora. London: Routledge.

Caglar, Ayse. 1997. Hyphenated Identities. In T. Modood and P. Werbner (eds.), The Politics of Multiculturalism in the New Europe, 169-185. London: Zed Books.

Clifford, James. 1997. Routes: Travel and Translation in the Late Twentieth Century. Cambridge, MA: Harvard University Press.

Derderian, Richard L. 1997. Broadcasting from the Margins: Minority Ethnic Radio in Contemporary France. In A. Hargreaves, A. McKinney (eds.), Postcolonial Cultures in France, 99-114. London: Routledge.

Hall, Stuart. 1992. The Question of Cultural Identity. In S. Hall, D. Held and T. McGrew (eds.), Modernity and its Futures, 21-33. Cambridge: Polity.

Huntington, Samuel. 1993. The Clash of Civilizations. Foreign Affairs 72, 3, 22-28.

INSEE. 1994. Les Étrangers en France. Paris: Hachette.

Joffe, Von Josef. 2000. How Is My "Leitkultur" Doing? Multiculturalism Meets Germany, Unleashing Angst, Ideological Reflexes and a Long-Overdue Debate. Die Zeit. Available at http://www.zeit.de/2000/45/Politik/200044_josefjoffe_1103.html.

Naficy, Hamid. 1993. The Making of Exile Cultures: Iranian Television in Los Angeles. Minneapolis: University of Minnesota Press.

Richie, Alexandra. 1998. Faust's Metropolis: A History of Berlin. New York: Carroll \& Graf.

Safran, William. 1991. Diasporas in Modern Society: Myths of Homeland and Return. Diaspora 1, $83-99$.

Schiffauer, Werner.1997. Islam as a Civil Religion: Political Culture and the Organisation of Diversity in Germany. In T. Madood and P. Werbner (eds.), The Politics of Multiculturalism in the New Europe, 147-166. London and New York: Zed Books.

Vertovec, Steven. 1996. Berlin Multikulti: Germany, "Foreigners" and "World-Openness." New Community 22, 3, 381-99.

Voss, Friedrich. 2000. Does Ethnic Broadcasting Have a Future? A Snapshot from Europe. Paper presented at the Ethnic Community Broadcasters Conference, Sydney 3-5 November, 2000. 